\title{
yor wort.
}

Bei ihrem erften Eridjeinen (1870) follte biefe mit ber - feitbem vielfac gebraudten - Bezeidnung - Textaugagabe mit 2lnmerfungen" veriehene 2usgagabe

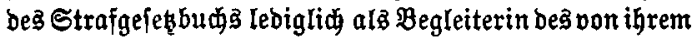
Begrünber bearbeiteten Rommentars bienen uno nebert einem forreften Befef̧estert nur bie nothinenbigften namentlid ben Z3ujammenhang bes allgemeinen unb beş befonberen Theils verbeutlidente - Beigaben nebịt Megiffter enthalten.

Die grobe Berbreitung bes Werfdaens veranlabte eine Erweiterung beffelben. Den Berfaffer leitete babei

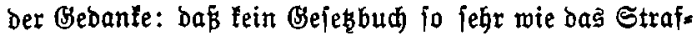

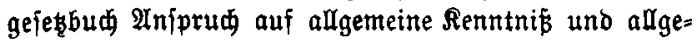
meinea Berftänonifí erhebt, 一 unb ber \$unid: bie Erfülung biefes 2rniprudis für den eritgeborenen Robec

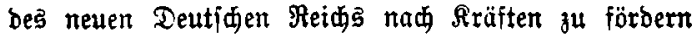

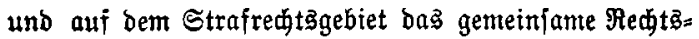
bemustiein lebendig zu erfalten, weldes, befonbers in

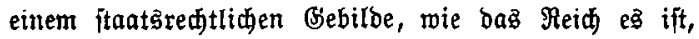
bas Z Ferment Der Befeggebung bleiben muk. Diejen 3roecten bient bie forgfältig ermogene innere und äußere Einridtung bes Büdleins. Daffelbe mill ein ftetş parates Sülfâmittel für ben Jutriften und saien, mie namentlid 
füt ben Stubirenben barbieten unb zur Berbreitung joliber ftrafredtrider Renntniffe in beldeibenen (Grenjent mitwirler. Die neue (20.) Ifuflage ift entipredenb bem Bange bet Bejeggebung unb Fedtipredung vermegrt;

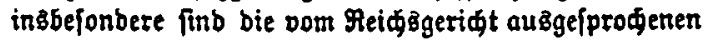

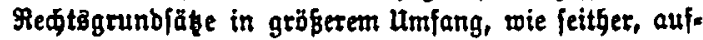
genommen. Pranderlei \$infe unb \$ünide baben Derüfidtigung gefunben. Die Refer werben gebeten, etwaige weitere $\mathfrak{B u ̈ n f d e ~ f u ̈ r ~ f p a ̈ t e r e ~ S u f l a g e n , ~ f o w i e ~}$ bemerlte Druaffebler u. bgl. bem Berfaffer ober betr Betlug auf einer Rarte mitjutbeilen. Sebe Inregung obet Mittbeilung witb banlbar entgegengenommen wetben.

Berlin, in Juli 1900. 